\title{
Using Social Life Cycle Assessment to analyze the contribution of products to the Sustainable Development Goals: a case study in the textile sector
}

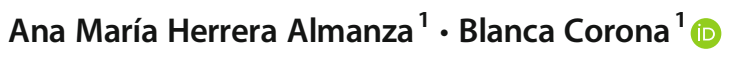 \\ Received: 28 January 2020 / Accepted: 30 June 2020 / Published online: 8 July 2020 \\ (C) The Author(s) 2020
}

\begin{abstract}
Purpose Evaluation and monitoring systems are perceived as an effective tool to understand and improve the contribution of business activities to the accomplishment of the Sustainable Development Goals (SDGs). However, there is currently a lack of guidance and support on assessing the influence that the life cycle of products and services has on the SDGs. This article presents a case study where Social Life Cycle Assessment (S-LCA) is applied to understand the social performance of a textile product and its potential contribution to the SDGs.

Methods In this study, the link between the S-LCA methodology and the SDG framework was made at the indicator level, through a new classification of S-LCA indicators. This classification was aimed at indicating the positive or negative contribution of products or services into the SDGs. The method was tested with the case study of a man's shirt whose supply chain takes place across five countries, from the cotton farming in China to the retailing in The Netherlands. The social performance of the shirt's life cycle was analyzed through a social hotspot assessment (using PSILCA database) and a site-specific assessment following the UNEP/SETAC S-LCA guidelines. Primary data was collected for 6 different suppliers regarding 51 social indicators and four stakeholder categories (workers, local communities, value chain actors, and society).

Results and discussion The social hotspot assessment indicated high social risks on indicators related to the following SDGs: health and well-being, affordable and clean energy, decent work, and responsible production and consumption. These risks were mainly located in Bangladesh (shirt manufacturing) and Malaysia (fabric manufacturing). The site-specific assessment indicated different results than the social risk assessment, showing worse social performance in the spinning stage (located in China). Negative scores were obtained for every supplier in at least four indicators, including working hours, safe and healthy living conditions, and access to immaterial resources.

Conclusions The results indicated negative social performance of the supply chain in most of the SDGs and identified points of improvement for the final retailer. The linkage of the S-LCA framework with the SDGs presented methodological challenges, mainly related to the different scope of the SDG indicators and the S-LCA indicators.
\end{abstract}

Keywords S-LCA · SDG $\cdot$ Social hotspot $\cdot$ Textile $\cdot$ Supply chain $\cdot$ Product level

\section{Introduction}

Responsible editor: Marzia Traverso

Electronic supplementary material The online version of this article (https://doi.org/10.1007/s11367-020-01789-7) contains supplementary material, which is available to authorized users.

Blanca Corona

b.c.coronabellostas@uu.nl

1 Copernicus Institute of Sustainable Development, Utrecht University, Vening Meinesz building A, Princetonlaan 8a, 3584 CB Utrecht, The Netherlands
In 1992, the United Nations declared sustainability as the main political goal to achieve future development (United Nations, 1992) and created a blueprint for sustainable development implementation (the Agenda 21). Eight years later, seven time-bound and measurable sustainability goals (the Millennium Development Goals) were agreed by the UN as a worldwide strategy to increase sustainability (United Nations 2019a). While some of these goals were achieved by the target date in 2015, some sustainability issues (e.g., gender inequality or environmental degradation) were still in 
need of further progress. This prompted in 2015 the introduction of seventeen Sustainable Development Goals (SDGs) (see Box 1), aimed at shaping the sustainable development agenda for a more prosperous, inclusive, and sustainable society by 2030 (United Nations 2019a). The SDGs are organized into a global indicator framework, developed by the Inter-Agency and Expert Group on SDG Indicators (United Nations 2019b). According to this framework, each of the seventeen SDGs includes a list of targets, whose progress is measured through indicators (in total, 230 indicators).

Fulfillment of the SDGs requires actions worldwide, not only from governments but also from the business and industrial sectors. An effective way to understand and improve the effects of business into the SDGs is the use of monitoring and evaluation systems (Scheyvens et al. 2016). Such systems can serve as guidelines for improvement, since they can point out main business opportunities and threats in the road to SDG accomplishment. Several tools and frameworks have been developed by scholars, governmental institutions, and consultancy firms trying to map, report, and even engage the SDGs into business strategies. Some of them are designed for a specific case study or field, and others are applicable to any kind of field/business. Examples of the latter are the SDG Compass framework by the UN, which guides in the visualization of the organizational contributions to the SDGs, or the Global Reporting Initiative (GRI) guidelines for reporting the impact of the organizational activities over the SDGs. The SDG Selector framework proposed by the PWC helps in identifying which SDGs should be embraced by a company due to their relevance according to the business activities (PWC 2015). However, there is a lack of guidance and support on how to introduce, implement, and assess the contribution of product supply chains to the SDGs while considering a life cycle perspective (Weidema et al. 2018).

Box 1The 17 Sustainable Development Goals

Sustainable Development Goals

Goal 1: No poverty

Goal 2: Zero hunger

Goal 3: Good health and well-being

Goal 4: Quality education

Goal 5: Gender equality

Goal 6: Clean water and sanitation

Goal 7: Affordable and clean energy

Goal 8: Decent work and economic growth

Goal 9: Industry, innovation, and infrastructure

Goal 10: Reduced inequality

Goal 11: Sustainable cities and communities

Goal 12: Responsible consumption and production

Goal 13: Climate action

Goal 14: Life below water

Goal 15: Life on land

Goal 16: Peace and justice strong institutions

Goal 17: Partnerships to achieve the goal
Life cycle assessment (LCA) has been identified as a potential tool that could be used to measure the progress of business activities and products into the SDG (Goedkoop et al. 2017). The LCA methodology is considered the most appropriate methodology to assess the environmental impacts of products or services along their supply chain, from the extraction of raw materials until their final disposal (European Commission 2003). Although the original methodology is mainly focused on environmental impacts, it has also been expanded to cover economic and social impacts through the Life Cycle Costing and Social Life Cycle Assessment (SLCA) methodologies. S-LCA methodology is still at early stages of development (Martínez-Blanco et al. 2015), due mainly to the complexity of social systems and the difficulty of translating qualitative data into quantitative indicators (Corona et al. 2017; Kühnen and Hahn 2017). Nevertheless, its application and development have been intense in the last years, aiming at providing high-quality assessments of the social impacts related to products, services, and organizations.

There are a few studies linking LCA-derived indicators with the SDGs, mainly focusing on environmental LCA indicators (JRC 2019), and to a lower extent, on S-LCA indicators. Vermeulen (2018) discussed the inclusion of the SD agenda into the endpoint and midpoint impacts of Life Cycle Sustainability Assessment (LCSA). ${ }^{1}$ By revising each of the SDGs (and sub-goals), Vermeulen detected that only $25 \%$ of the SDGs were formulated in terms of endpoint impacts (achieved social well-being), and most of the sub-goals (39\%) were formulated in terms of policy outputs (e.g., plans or regulations). Additionally, the SDGs focus mostly on government roles, while LCSA is more focused on business and other actors. Vermeulen proposed an integrated LCSA framework aligned to the SDGs, where some goals were linked to midpoint impacts and others to endpoint impacts. Eisfeldt and Ciroth (2017), developers of the S-LCA database PSILCA, showed how the results of a social hotspots analysis with PSILCA could be used to support progress on several SDGs (in particular, SDGs 5 and 8). Wulf et al. (2018) linked 32 out of the 54 social indicators provided by the PSILCA database, together with other environmental and economic indicators (calculated with E-LCA and LCC methodologies) to the SDGs. The study differentiated two different levels of linkage with the SDGs: (1) at the goal level (linking indicators that aligned to the general aim of the 17 SDG goals) and (2) at the indicator level (linking indicators that align with the SDG indicators proposed by the UN global indicator framework). They specified that some important social issues (such as forced labor) were not included in the SDG indicators.

\footnotetext{
${ }^{1}$ Midpoint impacts typically represent the change (increase or decrease) of specific pollutants or undesired issues (e.g., increased $\mathrm{kg} \mathrm{CO}_{2}$ eq in the atmosphere), while endpoint impacts relate to the severity of the consequences of such change on areas of protection (e.g., the damage of such $\mathrm{CO}_{2}$ eq increase in the human health, measured in years of life lost).
} 
Likewise, they also found several SDGs (at the goal and indicator levels) that were not addressed by the LCSA methodologies (e.g., SDGs 2 and 11 at the goal level, and SDGs 5, 9, 13 , and 15 at the indicator level). The mismatch between goal linkage and indicator linkage was related to the different perspective of the frameworks. For instance, although the SDG 13 aims at combating climate change, the E-LCA indicator is related to mitigation, while the SDG indicator is related to adaptation. In line with Vermeulen's findings, Wulf et al. (2018) concluded that the macro level of the SDGs rarely fits with the micro level of product assessments, which hinders a clear understanding of the contribution of products to the SDGs.

Aside from the abovementioned studies, the current literature exploring the link between LCA and SDGs is scarce, and research and case studies are needed to better understand the opportunities and possibilities. This study has a double aim, enabled by a case study on the textile sector: (1) exploring the possibilities of using S-LCA results to understand the potential contribution of specific products and services to the SDGs, and (2) dive into the social impacts along the supply chain of textile products, where social impacts have been scarcely assessed in detail from a life cycle perspective. The first aim is methodological in nature, while the second aim is focused on the social performance of a textile product. The textile and apparel industry is especially relevant for social sustainability, due to the negative social impacts that affect many of the stakeholders involved in these supply chains (Köksal et al. 2017). For instance, workers' wages have declined by $25 \%$ in the last decade and usually do not provide for living standards (Annapoorani 2017; Wick 2009). Overtime is not duly regulated in countries with high production of textile products; e.g., Bangladeshi factories have an average of $28 \mathrm{~h} /$ week of overtime, where the legal maximum allowed is $12 \mathrm{~h} /$ week (Asif 2017). Child labor still has 12\% of global presence according to the latest International Labor Report (ILO 2017). Besides, there are reports of repression against labor unions and gender discrimination related to sexual harassment, abuse, and lower income earnings than male counterparts (Annapoorani 2017; Asif 2017; Wick 2009). Finally, workers' and local communities' health are in continuous risk due to the poor infrastructure and machinery of factories. These have generated noise pollution - many textile machines located in single rooms can reach cumulative noise levels by at least $5 \mathrm{~dB}$ beyond maximum noise levels (Jayawardana et al. 2014) - , lethal fires - eight of them in Bangladeshi factories since 2005-2018, leaving 414 deaths-- and building collapses, where the most remembered one was the Rana Plaza Building on April 24, 2013, leaving at least 1129 deaths (Anner et al. 2013).

However, just a few S-LCA peer-reviewed case studies have been published on textile products, mostly based on general social risk assessment, or focused on a few stakeholder categories. One study performed a complete S-LCA based on the UNEP/SETAC Guidelines (UNEP-SETAC Life Cycle Initiative 2009), to a woven garment made in an Italian factory (Lenzo et al. 2017) where only the stakeholder workers and local community were assessed. The study highlighted the difficulty in obtaining site-specific data from suppliers and customers but identified S-LCA as a valuable tool to support business decisions regarding social impacts. Other case studies looked at the social life cycle risks of different textile products by assessing social hotspots with the Social Hotspots Database (SHDB). These assessments were focused on textile products (e.g., shirts, jeans, and dresses) commercialized in Scandinavian countries and produced in Asian countries (Roos et al. 2016; Valente et al. 2015; Zamani et al. 2018). They highlighted the risks of child labor, low wages, and carcinogenic exposure within the related sectors in China and Bangladesh. Another study explored the social life cycle impacts of clothing items in the workers category, through the monetization of external socioeconomic costs (van der Velden and Vogtländer 2017). This study found that the social hotspots of the production chain from six standard clothing items were the Indian cotton fields and the Bangladesh garment factories.

This article provides a complete case study of a man's cotton shirt, using primary data from the shirt's production units and looking at four stakeholder categories.

\section{Methods}

This study is based on the methodology proposed by the SLCA guidelines published by the UNEP-SETAC Life Cycle Initiative (UNEP-SETAC Life Cycle Initiative 2009). The methodology is based on the same four steps as indicated for environmental LCA in the ISO series 14040 (ISO 2006): (1) definition of goal and scope, (2) life cycle inventory analysis, (3) life cycle impact assessment, and (4) interpretation. The first two steps are detailed in Sections 2.1 and 2.2, respectively, and the last two steps are detailed in Sections 3 and 4.

The procedure to link the S-LCA methodology with the SDGs is explained in Section 2.4.

\subsection{Goal and scope definition}

The goal of this S-LCA was to assess the social sustainability performance of a man's shirt, by mapping and identifying social impacts and points of improvement along the products' life cycle. The shirt under study is currently commercialized by a fashion chain based in The Netherlands. The results of this assessment were used to propose action plans that mitigate current and potential negative social impacts affecting the SDG accomplishment. The assessment was conducted in two steps: (1) a social risk hotspots assessment and (2) a site- 


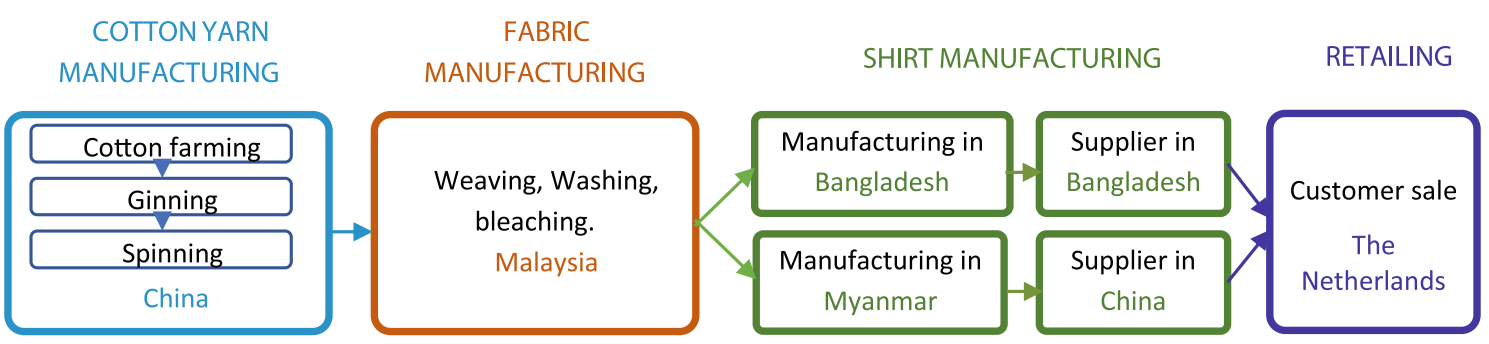

Fig. 1 System boundaries and supply chain of the shirt under study

specific assessment. The first assessment was conducted in order to identify points of the supply chain where social risks are higher, and therefore, site-specific data search should be prioritized. This first assessment also gave information on the social risks for one of the suppliers that could not be identified for the site-specific assessment (the cotton farmer). The second assessment was performed in order to map the main negative and positive social issues per SDG and identify points of improvement.

The functional unit for this study was defined as "a white, long-sleeve, medium size (M) man's shirt, of $243 \mathrm{~g}$ weight, and made of $97 \%$ cotton and $3 \%$ elastane." This garment is worn by men, mainly for working and assisting to special events. Due to the insignificant weight share of the elastane (3\%) and the plastic buttons contained in the shirt (1\%), these two components were not included in the study.

The current supply chain of the shirt includes the countries of China, Malaysia, Bangladesh, Myanmar, and The Netherlands. Figure 1 shows the simplified system boundaries and supply chain of the shirt under study. Raw material extraction and adaptation (ginning and spinning) occur in China. The cotton yarn is then sold to a textile mill located in Malaysia, where fabric is produced (including weaving, washing, and bleaching). Afterwards, the fabric is sold to apparel factories, or better known in the industry as ready-made garment (RMG) factories, located in Bangladesh and in Myanmar. The finished garment is then delivered to the factories that commanded the order, in Bangladesh and China, respectively, whose only contribution to the supply chain is the performance of a final quality control inspection before delivering the shipment to the apparel retailer in The Netherlands. The exact companies involved in the supply chain are kept anonymous due to confidentiality agreements.

Four stakeholder categories were considered in the study: workers, local communities, value chain actors, and society. The stakeholder category related to consumers was not included in the study, since the system boundaries were defined as from "cradle to gate," and only the production and retailing of the shirt were analyzed. Thirty sub-categories related to the aforementioned stakeholder categories were analyzed, as reported in Table 2. These sub-categories were defined considering the UNEP/SETAC S-LCA methodological sheets (Benoît Norris et al. 2013).
The social performance of the shirt was assessed following a two-step approach. First, a social hotspots ${ }^{2}$ analysis was performed in order to detect potential social risks in the shirt's supply chain. This analysis was conducted using the PSILCA database and the SimaPro software. Second, a site-specific social assessment was performed considering primary data on the supplier's social performance, and considering the social categories proposed by the UNEP/SETAC Guidelines (see more information on Section 2.3).

\subsection{Life cycle inventory analysis}

Two types of data were collected for this research: general data and site-specific data. General data relates to the potential social risks found at the industrial sectors involved in the value chain of interest, and site-specific data relates to social issues taking place in the production sites of the shirt's value chain.

\subsubsection{Data collection for the social hotspots analysis}

The Psilca database implemented in the SimaPro software was used to obtain and explore the life cycle social risks associated with the sectors directly involved in the shirt supply chain, in a so-called hotspots analysis. All the available indicators of the PSILCA database were used in the social hotspots analysis, although only 43 indicators (out of 49) were later classified into SDGs (as explained in Section 2.4). The social hotspots analysis required the use of primary data regarding monetary demands to each economic sector directly involved in the supply chain. Therefore, cost inventory data was collected and used to model the supply chain with PSILCA. This information was obtained by asking to each supplier for their endproduct's selling price. The provided prices were converted into the currency used by the PSILCA database (USD), considering inflation rates for each country. For the production units upstream of the shirt manufacturer, the given values required the conversion to a value per functional unit. Finally, the calculated values per functional unit for every supplier were modeled as the monetary demand to the country

\footnotetext{
${ }^{2}$ A social hotspot refers to a specific situation within a region that can be regarded as a problem, a risk, or an opportunity in terms of social concern (UNEP-SETAC Life Cycle Initiative 2009).
} 
economic sectors (CES) representing each activity of the supply chain. Table 1 contains the CES selected in PSILCA to represent the activities of the shirt's life cycle, and the corresponding monetary inputs. The retailer indicated two different manufacturers for the shirt, one located in Myanmar and the other one in Bangladesh. In order to account for the potential social risks occurring in both countries, it was assumed that half of the supply was provided by the Myanmar's textiles and wearing apparel sector and the other half by the corresponding Bangladeshi sector. The amount of monetary input required by each CES was adjusted accordingly.

\subsubsection{Site-specific data collection}

Site-specific data was collected through questionnaires sent to each production unit of the supply chain. The questionnaires contained 64 questions, addressing indicators from every subcategory considered under the scope of the research. The indicators were chosen following the recommendations from the UNEP/SETAC methodological sheets (Benoit Norris et al. 2013), and describe objective situational features that are objectively verifiable (Kühnen and Hahn 2017). The indicators used in this study are, therefore, not an indication of how stakeholders subjectively experience the indicated situational feature. A total of 51 indicators were gathered for this study, of which 21 indicators corresponded to the workers stakeholder category, 17 indicators to local communities, 7 indicators to value chain actors, and 6 indicators to society. The complete questionnaire and list of indicators chosen for each subcategory are available in the Supporting Information. Eight questionnaires were filled out by the managers of the production units, except for the Dutch retailer questionnaire that was filled by the corporate social responsibility (CSR) manager. Every unit in the supply chain completed the questionnaire except for the Chinese cotton farmer, who could not be identified. Therefore, the cotton cultivation was excluded from the site-specific assessment. The questionnaires were distributed in English, except for the one filled out by the Chinese production unit that was translated into Chinese.

Specific information was also gathered regarding the worker hours of each company involved in the supply chain. This information was used as activity variable for the aggregation of characterized results along the shirt's life cycle (see Section 2.3 for more information on activity variables).

\subsection{Life cycle impact assessment}

The impact assessment step in this analysis follows the type 1 approach. This approach uses performance reference points (PRP) to assess the social performance of the company, by comparing the indicator results of the shirt's life cycle with social international standards (UNEP-SETAC Life Cycle Initiative 2009).

\subsubsection{Social hotspots assessment}

The generic social hotspots assessment was performed with SimaPro, by using the method provided by the PSILCA database (Eisfeldt and Ciroth 2018). This method assesses the indicators by assigning different risk levels depending on the value of the indicator. Typically, six levels are distinguished, ranging from no risk to very high risk. The activity variable used to reflect the relevance of each activity within the life cycle is worker hours, and the risk assessment result for every

Table 1 Inventory inputs for the social risk assessment of the shirt's life cycle

\begin{tabular}{|c|c|c|c|c|}
\hline Life cycle stage & End product & $\begin{array}{l}\text { Purchase cost/FU, in } \\
\text { USD } 2015\end{array}$ & Country economic sector (PSILCA) & $\begin{array}{l}\text { Input value (PSILCA), in } \\
\text { USD } 2015\end{array}$ \\
\hline Cotton cultivation & Raw cotton & 0.23 & Crop cultivation/China $(\mathrm{CN})$ & 0.23 \\
\hline Cotton ginning and spinning & Cotton thread & 1.69 & Cotton textiles/China $(\mathrm{CN})^{*}$ & 1.69 \\
\hline Fabric manufacture & Cotton fabric & 4.53 & Knitted fabrics/Malaysia (MY)* & 4.53 \\
\hline $\begin{array}{l}\text { Shirt manufacturing }(50 \% \\
\text { in Myanmar and 50\% in }\end{array}$ & $\begin{array}{l}\text { Cotton shirt from } \\
\text { Myanmar }\end{array}$ & 5.19 & $\begin{array}{l}\text { Textiles and wearing } \\
\text { apparel/Myanmar }(\mathrm{MN})^{*}\end{array}$ & 2.60 \\
\hline Bangladesh) & $\begin{array}{l}\text { Cotton shirt from } \\
\text { Bangladesh }\end{array}$ & 5.72 & $\begin{array}{l}\text { Textiles and wearing } \\
\text { apparel/Bangladesh (BD)* }\end{array}$ & 2.86 \\
\hline Clothing retailing & $\begin{array}{l}\text { Cotton } \\
\quad \text { commercialization }\end{array}$ & 29.35 & $\begin{array}{l}\text { Retail trade, except for motor } \\
\text { vehicles and } \\
\text { motorcycles, repair of personal } \\
\text { and household } \\
\text { goods/The Netherlands (NL)* }\end{array}$ & $23.89^{\dagger}$ \\
\hline
\end{tabular}

*Only the direct social risks from these sectors were included in the model (and not the indirect social risks associated with inputs from other sectors). This was done in order to avoid two issues: (1) double counting of risks from directly demanded sectors who are indirectly demanded by other sectors already included in the model, and (2) influences of exports and imports from countries not directly related to the supply chain under study

$\dagger$ The input amount was calculated by subtracting the shirt's manufacturing price from the selling price of the retailer 
indicator is normalized into "medium risk hours" by assigning different factors to the different risk levels. The PRP used to estimate the risk levels are based on international conventions and standards, expert opinions, and the database developer's experience and evaluation.

\subsubsection{Site-specific assessment}

The PRP for the site-specific assessment were retrieved from the International Labor Organization (ILO) conventions, the ISO 26000 guidelines, the OECD Guidelines for Multinational Enterprises, the IFC Performance Standards on Social and Environmental Sustainability, Occupational Safety and Health Administration (OSHA) protocols and codes of conducts, and certifications like the BSCI and SA8000. The social performance in each sub-category was assessed by characterizing the indicator according to six levels: A: representing much better than above compliance; B: above compliance; C: compliance; D: not compliance; and $\mathrm{E}$ : worse than no compliance. A compliance level $\mathrm{C}$ was awarded when the supplier performed as indicated by the PRP. For instance, if the PRP to evaluate "number of overtime hours per week" indicated that the overtime should not exceed $12 \mathrm{~h}$ per week, indicators reporting $12 \mathrm{~h} /$ week would get a C level, indicators of 7-11 h/week would get a B level, and indicators with less than $6 \mathrm{~h} /$ week would get an A level. On the contrary, indicators reporting $13-16 \mathrm{~h} /$ week would obtain a D level, and more than $17 \mathrm{~h} /$ week an E level. The PRP chosen as reference for each indicator and the assigned rankings are described in detail in the Supporting Information.

Following the proposal by Corona et al. (2017), a quantitative value measured in social performance points (SPP) was assigned to each of these levels to transform qualitative data into quantitative data. Thus, A obtained 2 SPP, B obtained 1 SPP, C obtained 0 SPP, D obtained - 1 SPP, and E obtained 2 SPP.

After all the values per indicator and unit process were obtained, results for each indicator were combined into a weighted average. The positive and negative values obtained in each unit process (for each supplier in the value chain) were aggregated into a weighted average, using worker hours as weighting factor or, in other words, as activity variable. For instance, if the indicator "overtime payment rate" is assigned 1 SPP in one life cycle activity and - 2 SPP in a second activity, the aggregated value is - 1 SPP when assuming same weights for both activities. The choice of worker hours as activity variable is disputable, since not every social issue is directly related to the worker hours involved in the supply chain (e.g., social issues related to local communities or value chain actors). In order to address the sensitivity of the results with respect to the activity variable, two different sets of worker hours were considered for a sensitivity analysis. The first set (T1) considered activity variable the total amount of hours worked by all the employees of each company, assuming that a bigger company (with more workers) has a higher influence in every stakeholder and social issue than a smaller company, independently of the hours allocated to the functional unit of the study. This activity variable implies that the social effects of companies with big workforces are higher (both for negative and for positive social issues) than companies with small workforces. The second set (T2) considered activity variable the exact amount of worker hours needed to produce the shirt by each company. This value was determined by considering the worker hours allocated to each supplier by the PSILCA database (e.g., the number of worker hours to manufacture the shirt in Myanmar is calculated by multiplying the costs of manufacturing one shirt in Myanmar by the worker hours needed by such sector to supply one monetary unit of product).

The results obtained in each indicator were not weighted into a final aggregated value of social performance due to the high value load of weighting factors. Therefore, results were presented separately in an easy-to-visualize layout that allowed identifying the main negative and positive social issues along the supply chain.

\subsection{Linking the SDGs with the S-LCA indicators}

The link between the S-LCA results and the SDGs was made at the indicator level (midpoint level). The S-LCA results per indicator (for both the general and the site-specific assessment) were classified depending on their relevance for each of the 17 SDGs. The classification was made by exploring the SDG targets, the corresponding indicators proposed by the $\mathrm{UN}$ to measure progress in each SDG (United Nations 2019b), and their concordance with the S-LCA indicators. The UN SDG indicators are aimed at the macro level (e.g., global indicators measuring countries' performance), but the site-specific S-LCA indicators are aimed at the micro level of companies, products, or services. Therefore, the linkage of the site-specific S-LCA indicators with the general goals and targets resulted to be more appropriate than with the specific UN indicators, which goes in line with the findings of Wulf et al. (2018). However, some indicators in the PSILCA database (which is based on input-output tables at a macro level) could, and were, directly linked with the macro-level indicators of the SDGs. After the classification process, 43 indicators from the PSILCA database were classified into 10 SDGs, and 51 site-specific indicators were classified into 11 SDGs. In order to give an indication of the magnitude of the risks and main hotspots within each SDG, the results obtained in the social hotspots assessment (with PSILCA indicators) were aggregated by considering equal weights for every indicator classified into an SDG. The complete classification and basis for the linkage are included in the Supporting Information. The indicator results for the site-specific assessment were classified 
into the SDGs but not weighted into a single value per SDG, since a visualization of the main negative and positive social issues per SDG at the indicator level was found more transparent and useful for the goal of the study than a weighted aggregation of indicators.

During the classification, it was found that the S-LCA indicators are currently not detailed enough in terms of discrimination issues, contrary to the SDGs, where discrimination issues are measured through many indicators in several different goals (e.g., regarding gender and access from indigenous communities to education and income). Furthermore, no related indicators were found for SDGs 2, 13, 14, 15, and 17. However, some of these SDG are aimed at environmental preservation (e.g., goals 13, 14, and 15), which is addressed by environmental LCA and is usually out of the S-LCA scope. It should also be noted that some SDGs could be addressed by considering the purpose and practices around specific types of products, i.e., by the function and opportunities provided by the product. For instance, the life cycle of an agricultural food product would necessarily contribute to some extent to SDG 2. Therefore, further examination of the SDGs should be carried out for different types of products. Clothing items are important since they typically protect the body from environmental hazards and help to define and transmit the cultural identity of the user. Although there are no SDG targets directly related to the function of clothing, clothes could be contributing to targets of SDG 3 (healthy lives and well-being) when they are aimed at reducing the risks of illnesses or accidents. For instance, advanced clothes can be developed to prevent mosquito bites while ensuring transpiration, or designed to protect against accidents at the workplace (e.g., protecting gloves or shoes). On the other side, clothes can include messages that promote gender equality and sustainable behavior, and therefore, addressing targets of SDGs 4 and 5. In the case under study, a white male shirt, the function is to cover the body and give a formal and clean appearance to a male user. This specific function was not deemed to address any of the SDG targets.

\section{Results}

\subsection{Social hotspots assessment}

Figure 2 shows the potential social risks obtained in each PSILCA indicator, per life cycle stage and supplier, within the shirt's life cycle. As observed in Fig. 2, the social indicators presenting higher social risks are related to goals $3,7,8,12$, and 16 . In the goal 3 (good health and well-being), main risks are associated with low public health and social security expenditure in Bangladesh, followed by Myanmar and Malaysia. For affordable and clean energy (goal 7), the higher risks are associated with a high extraction of biomass (probably for energy purposes) in the activities of fabric weaving, shirt manufacturing, and retailing. This indicator from the PSILCA database assesses the risks of conflicts due to the exploitation of resources that are basic for the life and economy of local communities and organizations. The main risk for decent work and economic growth (goal 8 ) is related to a low trade union density rate in China, Bangladesh, and The Netherlands. For responsible consumption and production (goal 12), main risks are related to a low rate of certified environmental management systems per employee, in every sector (and mainly in China, Bangladesh, and The Netherlands). For the peace, justice, and strong institutions (goal 16), risks are related to low social responsibility in the supply chain, due to the low participation of the sectors in the UN Global Compact Initiative, and to high public sector corruption in Malaysia (knitted fabrics) and Bangladesh (wearing apparel) (according to the PSILCA database).

Low average risks were found in the indicators related to fair salary, safety measures, DALY's due to pollution, youth female illiteracy, forced and child labor, weekly hours, fatal accidents, mineral consumption, corruption, and unemployment. Although the aggregated risk for these social issues was relatively low along the supply chain, some of these issues indicated high risk of occurrence in specific sectors; for instance, a high risk of unfair salaries was found in the Bangladeshi garment sector. This is aligned to the results found by Zamani et al. (2018), where poverty due to wages under 2 USD in Bangladeshi garment factories was detected as a hotspot.

Figure 3 shows the potential social risks aggregated per SDG and life cycle stage (assuming equal weights for every indicator contributing to each SDG). According to the obtained results in Fig. 3, main social risks are related to the life cycle activities taking place during shirt manufacturing in Bangladesh for almost every SDG, followed by fabric manufacturing in Malaysia for SDGs 7, 10, 12, and 16, and retailing in The Netherlands for SDGs 5, 7, and 8. The Bangladeshi garment sector has been frequently associated with human rights violations and poor health and safety conditions of workers (Kamal 2013). Despite the international efforts in improving the social conditions of Bangladeshi workers, social risks from this sector are still high in most of the SDGs. The risk of international migrant workers in the sector is almost only present in the Malaysian knitting sector, which also presents high-risk share of forced labor and child labor. Since 2013, Malaysia became an emerging economy among the South Asian countries. This caused the migration of Southeast Asian people, both high and low skilled (the majority of them low skilled), into the Malaysian manufacturing industries (Jordaan 2018). 
Fig. 2 Results from the social hotspots analysis of the shirt under study, using the PSILCA database and evaluation method (CN, China; MY, Malaysia; MM, Myanmar; BD, Bangladesh; NL, The Netherlands). *Contribution to economic development is the only category presenting positive risks instead of negative risks. For further explanation of the indicators, see Eisfeldt and Ciroth (2018)

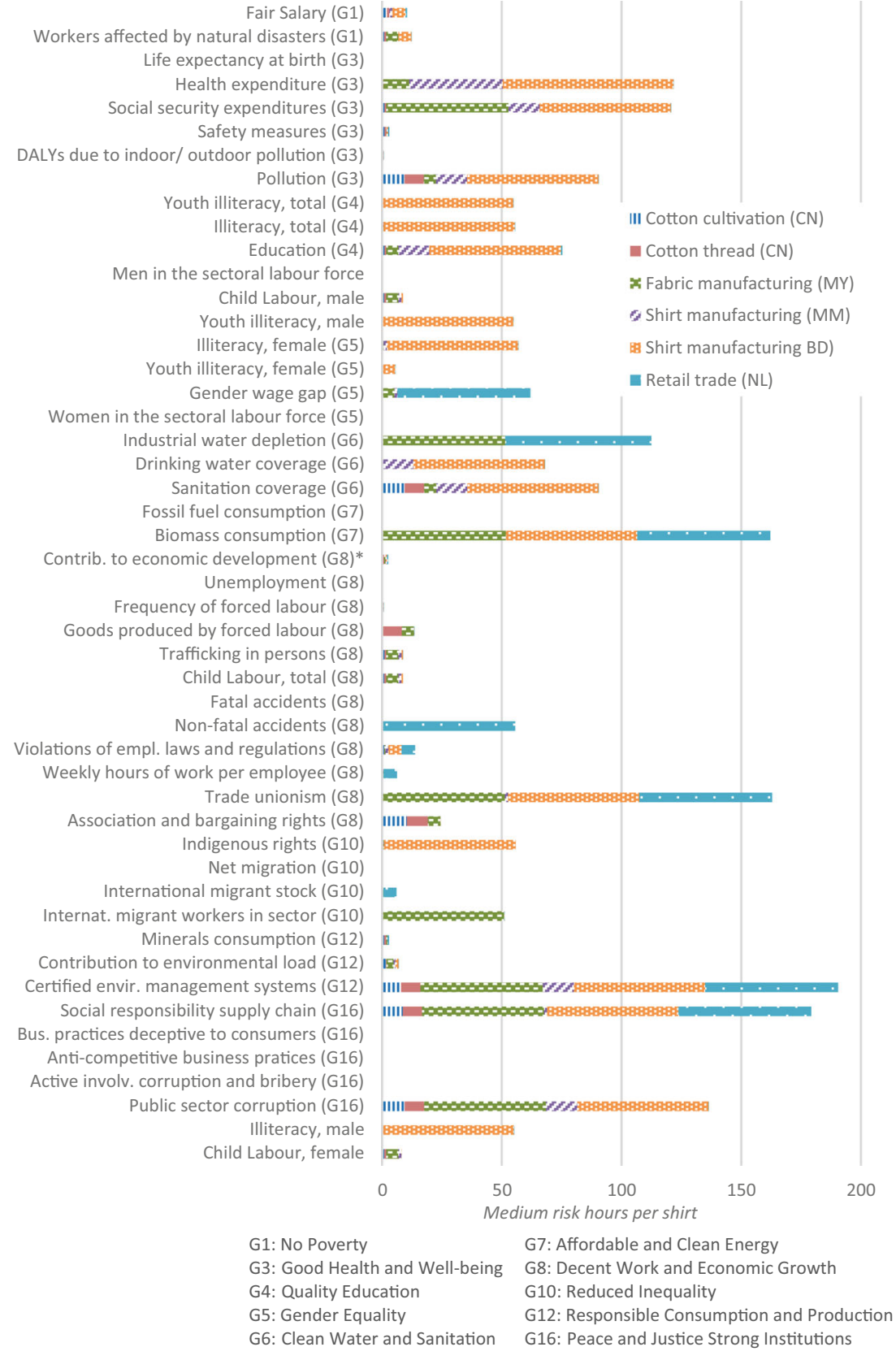

and a high risk of female illiteracy in the latter. According to the ILO global wage report 2018/2019, The Netherlands has the highest mean gender pay gap within the high-income economic group category. A possible cause to this gender wage gap may be that part-time jobs or reduced working shifts are mostly taken by women, due generally to personal and family chores. This scenario is not reflected in lower-middle income economies, where both men and women need to have fulltime jobs (and sometimes more than one job) in order to sustain their families. In Bangladesh for instance, only $10 \%$ of women and $4 \%$ of men have part-time jobs; meanwhile, in The Netherlands, $72 \%$ of women and $26 \%$ of men have parttime jobs (ILO 2018). 


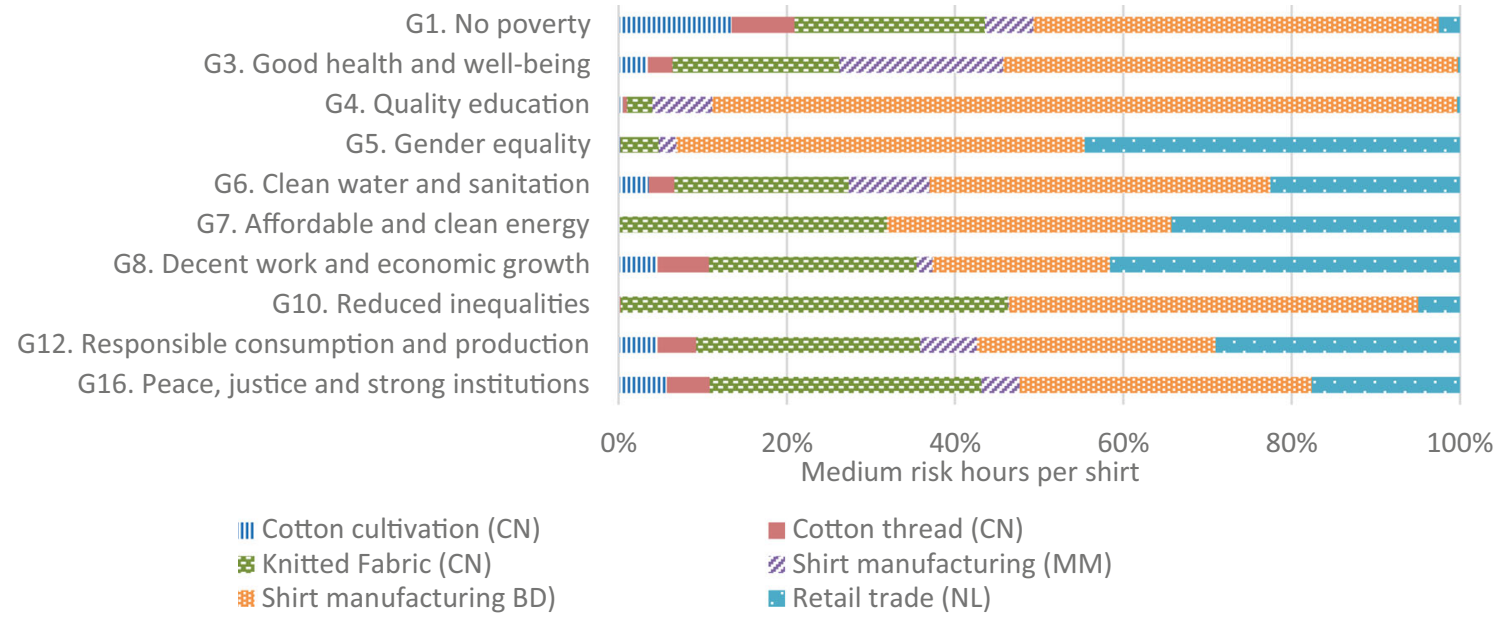

Fig. 3 Weighted social risks contributing to each SDG, per life cycle stage of the shirt under study

\subsection{Site-specific assessment}

Table 2 describes the results obtained from the site-specific assessment of the social performance along the shirt's supply chain. The table includes the characterized scores for all the indicators considered, classified per S-LCA sub-category and corresponding SDG. The characterized score per indicator and life cycle stage is represented with a different color depending on the social performance level achieved when compared with the corresponding PRP, ranging from dark green (better than above compliance) to dark red (worse than non-compliance). A complete list of the values (qualitative and quantitative) considered for each indicator and supplier is contained in the Supporting Information. The two columns in the right side of Table 2 include the aggregated value along the supply chain, for each indicator, considering two different sets of activity variables. The first set (T1) considers activity variable the total worker hours of the companies involved in the supply chain, independently of the functional unit of the study (this information was obtained through questionnaires). The second set (T2) considers activity variable the amount of worker hours allocated to the shirt, determined by the worker hours allocated to each supplier (or life cycle stage) within the PSILCA model (this information was obtained by combining the price of the items with the worker hours per monetary unit and sector indicated in the PSILCA database). The allocation factors considered for each set are described in Table 3. The first set (T1) gives more weight to the spinner and the shirt manufacturers, while the second set (T2) gives more weight to the fabric manufacturer and the retailer. The $\mathrm{T} 2$ weights allocated to the shirt manufacturer are significantly different between the two suppliers in Myanmar and Bangladesh. This difference is due to a different selling price per functional unit (FU) (higher in Bangladesh, see Table 1) and a considerably higher ratio of working hours per USD in the Bangladeshi sector (according to the PSILCA database). In both sets of results, the ginner gets only $1-2 \%$ of the weight.

Results indicate that every supplier scores negatively in at least 4 indicators. The spinner presents the worst performance, scoring neutrally or negatively in every indicator (22 indicators perform below compliance), while the retailer presents the less negative performance, with only 4 indicators performing non-compliance and six indicators performing above compliance. The ginner is the supplier that performs above compliance in a higher number of indicators ( 9 indicators performed above compliance or better, but 12 performed noncompliance).

The main negative social hotspots identified in the sitespecific assessment are related to (1) the number of hours worked per week in the cotton spinning $(60 \mathrm{~h}$ per week in average) and the shirt manufacturing in Bangladesh (average overtime of $36 \mathrm{~h}$ per week) and (2) an absence of a waste management system in the spinning stage.

The aggregated results indicate that every SDG presents at least one indicator with negative social performance. The negative performance of some indicators is especially high for the SDGs 3 and 4, due to low performance in safe and healthy living conditions and access to immaterial resources regarding education. However, these goals also present the most positive social performance of the shirt's life cycle, due to good (above compliance) social benefits provided to workers (especially by the ginner and the shirt manufacturer in Bangladesh). Other indicators presenting negative performance are related to:

- Equal opportunities (in SDG 5), due to a very low ratio of women in management positions in the fabric and shirt manufacturing (in China and Bangladesh, respectively);

- Working hours (in SDG 8), due to overtime hours per week in the spinning and manufacturing of the shirt (in China and Bangladesh, respectively); 
Table 2 Social performance of the shirt's supply chain for different indicators, classified per S-LCA sub-categories and SDGs. T1, aggregated average value considering company's total working hours as activity variable; T2, aggregated average value considering working hours per FU, according to model in PSILCA

\begin{tabular}{|c|c|c|c|c|c|c|c|c|c|c|}
\hline & S-LCA subcategory & Indicators & Ginner & Spinner & Fabric & $\begin{array}{l}\text { Shirt } \\
\text { MN }\end{array}$ & Shirt BD & Retailer & T 1 & T 2 \\
\hline G1 & Fair Salary & Lowest paid worker, compared to the minimum wage & & & & & & & 0.1 & 0.3 \\
\hline \multirow{5}{*}{ G3 } & Social Benefits \& Security & List of social benefits provided to the workers & & & & & & & 1.0 & 1.2 \\
\hline & \multirow{2}{*}{ Secure living conditions } & Management policies related to private security personnel & & & & & & & 0.0 & 0.0 \\
\hline & & Number of incidents ascribed to the organization due to insecurity conditions & & & & & & & 0.0 & 0.0 \\
\hline & Safe \& Healthy Living Conditions & Organization efforts to strengthen community health & & & & & & & -1.0 & -1.0 \\
\hline & Health and safety & Preventive measures and emergency protocols for pesticide $\&$ chemical exposure & & & & & & & 0.0 & 0.0 \\
\hline \multirow[t]{2}{*}{ G4 } & Access to immaterial resources & Presence/strength of community education initiatives & & & & & & & -1.0 & -1.0 \\
\hline & Social Benefits /Social Security & List of social benefits provided to the workers & & & & & & & 1.0 & 1.2 \\
\hline \multirow{2}{*}{ G5 } & \multirow{2}{*}{ Equal opportunities } & Ratio of basic salary of men to women by employee category & & & & & & & 0 & 0 \\
\hline & & Ratio of male and female employees in workforce and management positions & & & & & & & -0.6 & -0.6 \\
\hline \multirow[t]{2}{*}{$\overline{\mathrm{G} 6}$} & \multirow{2}{*}{ Access to material resources } & Adequate management of waste streams and wastewater discharge & & & & & & & 0.1 & 0.5 \\
\hline & & Presence of certified environmental management systems & & & & & & & 0.0 & -0.1 \\
\hline \multirow{18}{*}{ G8 } & Contribution to econ. development & Investments of innovations and new technologies & & & & & & & -0.2 & -0.1 \\
\hline & Fair Salary & Regular and documented payment of workers & & & & & & & 0.0 & 0.0 \\
\hline & Local employment & Strength of policies on local hiring preferences & & & & & & & -0.2 & -0.3 \\
\hline & & Presence of forced labor at the organization & & & & & & & 0.0 & 0.0 \\
\hline & Forced Labor & Retention of birth certificate, passport, or other original worker documents & & & & & & & 0.0 & 0.0 \\
\hline & & Workers' freedom to terminate their employment within the prevailing limits & & & & & & & 0.0 & 0.0 \\
\hline & Child Labor & Absence of working children under the legal age & & & & & & & 0.0 & 0.0 \\
\hline & \multirow{5}{*}{ Health and safety } & Existence of fire-fighting equipment and emergency exits & & & & & & & 0.0 & 0.0 \\
\hline & & Provision of medical assistance and first aid & & & & & & & 0.4 & 0.3 \\
\hline & & Access to drinking water & & & & & & & 0.0 & 0.0 \\
\hline & & Notification of occupational accidents, incidents and diseases & & & & & & & 0.0 & 0.0 \\
\hline & & Provision of protective gear & & & & & & & 0.0 & 0.0 \\
\hline & \multirow[t]{2}{*}{ Equal opportunities } & Presence of diversity in the workforce & & & & & & & 0.0 & 0.0 \\
\hline & & Number of hours worked per week & & & & & & & -0.1 & 0.2 \\
\hline & \multirow[t]{2}{*}{ Working Hours } & Number of overtime hours per week & & & & & & & -0.7 & -0.4 \\
\hline & & Overtime payment rate & & & & & & & 0.4 & 0.4 \\
\hline & \multirow{2}{*}{$\begin{array}{l}\text { Freedom of Association and } \\
\text { Collective Bargaining }\end{array}$} & Presence of unions within the organization & & & & & & & -0.2 & 0.0 \\
\hline & & Participation of employees' representatives in decisions affecting working conditions & & & & & & & -0.5 & -0.3 \\
\hline G9 & Technology development & Involvement and/or investment in technology transfer or research and development & & & & & & & -0.3 & -0.1 \\
\hline \multirow{4}{*}{ G10 } & \multirow{2}{*}{ Respect of Indigenous Rights } & Strength of policies in place to protect the rights of indigenous communities & & & & & & & -0.6 & -0.4 \\
\hline & & Annual meetings held with indigenous community members & & & & & & & -0.6 & -0.6 \\
\hline & \multirow{2}{*}{ Delocalization \& Migration } & Number of individuals who resettle that can be attributed to organization & & & & & & & 0.0 & 0.0 \\
\hline & & Strength of organizational procedures to integrate migrant workers into the community & & & & & & & 0.0 & 0.0 \\
\hline & & Strength of Policies in Place to Protect Cultural Heritage & & & & & & & -0.4 & -0.1 \\
\hline G11 & Cultural Heritage & $\begin{array}{l}\text { Is relevant organization's information available to community members in their spoken } \\
\text { language(s)? }\end{array}$ & & & & & & & -0.2 & 0.0 \\
\hline \multirow{3}{*}{ G12 } & Public commitments to & Presence of publicly available documents as promises or agreements on sustainability & & & & & & & -0.2 & 0.5 \\
\hline & sustainability issues & Engagement of the organization to present yearly communication on progress & & & & & & & -0.6 & -0.4 \\
\hline & Access to Material Resources & Management of hazardous materials & & & & & & & 0.0 & 0.0 \\
\hline \multirow{4}{*}{ G16 } & Community engrament & Organizational support (volunteer-hours or financial) for community initiatives & & & & & & & -0.4 & -0.5 \\
\hline & Community engagement & Number and quality of meetings with community stakeholders & & & & & & & -0.8 & -0.6 \\
\hline & Corruntion $>>$ & The organization cooperates with internal/external entities to prevent corruption & & & & & & & -0.2 & -0.1 \\
\hline & Corruption & The organization carries out an anti-corruption program & & & & & & & -0.3 & -0.6 \\
\hline & Fair Competition & $\begin{array}{l}\text { Documented statements or procedures to prevent engagement or complicity in } \\
\text { anticompetitive behavior }\end{array}$ & & & & & & & -0.2 & 0.0 \\
\hline & & Employee awareness of the importance of compliance with competition legislation & & & & & & & -0.2 & 0.0 \\
\hline & Supplier relationships & Payments on time to suppliers & & & & & & & 0.0 & 0.0 \\
\hline & & Presence of explicit code of conduct protecting workers human rights among suppliers & & & & & & & 0.0 & 0.3 \\
\hline & & Share of audited suppliers regarding social responsibility in the last year & & & & & & & -0.4 & -0.3 \\
\hline & Promoting social responsibility & Support to suppliers on social responsibility consciousness-raising and counselling & & & & & & & -0.6 & -0.4 \\
\hline & & Membership in an initiative that promotes social responsibility along the supply chain & & & & & & & 0.0 & 0.5 \\
\hline & Access to Immaterial Resources & Freedom of expression at the company & & & & & & & 0.2 & 0.3 \\
\hline
\end{tabular}

Better than above compliance

Above compliance

Compliance

Non-compliance

Worse than non-compliance

- Respect of indigenous community members (in SDG 10), due to absence of protective policies or annual meetings with local community members by the fabric and shirt manufacturers; and

- Public commitments to sustainability issues (in SDG 12), due to low engagement of most companies with sustainable initiatives and low communication of their achievements in the social and environmental dimensions.

Most of the indicators, especially in the SDG 8 (decent work and economic growth), presented a neutral performance (neither above nor below compliance of laws or international standards). These results can be interpreted as compliant with the SDG, but with no remarkable efforts towards SDG accomplishment.
The aggregated results when using two different activity variables presented a similar outcome in most of the indicators. Higher differences were observed in the indicator related to number of hours worked per week, which presented a slight negative performance for $\mathrm{T} 1$ and a slight positive performance for T2. This is due to the different weights given to the spinner and the fabric manufacturer in the two sets. In the first weighting set, the spinner-that presents a very negative performance - gets a higher weight (18\% weight in T1 vs. $3 \%$ weight in $\mathrm{T} 2$ ), while in the second set, the weaverpresenting a positive performance-gets a higher weight ( $28 \%$ in T2 vs. $22 \%$ in T1). A similar situation is observed in the indicator related to promises or agreements on sustainability. The $\mathrm{T} 2$ results show a positive performance due to the higher weight given to the retailer (30\% in T2 vs. 
Table 3 Allocation factors for each unit in the shirt's supply chain, according to two different activity variables

\begin{tabular}{|c|c|c|c|c|c|c|}
\hline & Ginner (\%) & Spinner $(\%)$ & Fabric manuf. $(\%)$ & Shirt manuf. (MN) (\%) & Shirt manuf. (BD) $(\%)$ & Retail (\%) \\
\hline $\begin{array}{l}1 \text { Allocation factors considering } \\
\text { total worker hours in companies }\end{array}$ & 2 & 18 & 22 & 18 & 37 & 3 \\
\hline $\begin{array}{l}2 \text { Allocation factors considering } \\
\text { worker hours per shirt (PSILCA values) }\end{array}$ & 1 & 3 & 28 & 7 & 30 & 30 \\
\hline
\end{tabular}

$3 \%$ in T1). However, most of the other suppliers perform badly in this indicator.

The findings of the study indicate a high potential for improvement along the supply chain in most of the SDGs, and especially in the spinning life cycle stage. Even though some indicators indicated better performance than international standards or regulations, and many indicators indicated a level of compliance (especially in SDG8), most of the indicators are presenting non-compliance or worse than non-compliance at some point of the supply chain.

\section{Discussion}

By classifying the S-LCA indicators into different SDGs, this study assessed the potential effect of the product's supply chain into the SDGs, and especially, the main points of improvement towards SDG accomplishment along the supply chain. The proposed approach gives an indication of which goals (and corresponding targets) are mostly affected (negatively or positively) by the product's social supply chain, but it does not give information about the degree of contribution to specific SDG indicators, i.e., how much the life cycle of a product is contributing to fulfill specific targets of the SDGs as defined by the UN SDG global indicator framework. Such degree of contribution was hard to measure due to the different scope of the SDG framework (macro) and the S-LCA framework (micro). Further integration could be achieved by using SDG-adjusted S-LCA indicators, and especially, by creating new PRP able to relate the scope of business activities to the current degree of global SDG accomplishment. Additionally, there are several social issues relevant to the SDGs that are not fully covered by the S-LCA framework. This includes social issues related not only to discrimination but also to environmental preservation (which could be potentially covered by environmental LCA).

In addition, social hotspots analysis conducted with databases such as PSILCA gives an indication of the main social risks at the macro level, aligning well with the scope of the SDGs. Most of the indicators in social hotspots risk assessments are related to statistic values at the macro level, which can be more easily linked to SDG targets. These analyses are useful to measure potential effects in the SDG of promoting economic activities in certain sectors, and to determine where are the main potential risks, and therefore opportunities, for positive or negative social change. For instance, our analysis indicated that whereas the textile sector in Bangladesh has high risks of performing poorly in many SDGs, the specific supplier in Bangladesh shows positive social performance. Therefore, this product is improving the current social situation of a sector where efforts are especially needed in order to fulfill the SDGs.

The utility of products that fulfill important functions for society is not currently covered by the list of indicators contained in the UNEP/SETAC methodological sheets (Corona et al. 2017). However, such utility is relevant for the SDG framework, offering a possibility for integration into the S-LCA methodology. By this framework, such integration could be made by considering if the function of a product clearly contributes to (or hinders) the fulfillment of specific SDGs.

This analysis provided several recommendations to the fashion Dutch retailer. The company should aim at implementing an environmental management system at the headquarters and improving their social management. At this respect, the company should ensure that the suppliers comply with international standards related to weekly hours, overtime hours, freedom of association, gender equality, and waste management systems, especially for the cotton spinner in China, and the shirt manufacturer in Malaysia. This would require more stringent audits (that the company is already performing in the frame of their CSR program) and a better understanding of the actors involved within the supply chain (the cotton farmer could not be identified by any of the supply chain actors). One of the risks of obtaining primary data by directly asking the suppliers is the underestimation of negative impacts. Although in this case the results indicated more negative performance than positive, it could still be the case that the suppliers did not report the most negative aspects of their social management.

In the presented case study, the results obtained through the social hotspots assessment indicated higher social risks for the shirt manufacturing (in Bangladesh), followed by the fabric manufacturing (in Malaysia). The risks in those production units were especially high in the indicators related to certified environmental management systems, trade unionism, and social responsibility. The site-specific assessment indicated different results than the social risk assessment, showing worse 
social performance in the spinning stage (in China). Additionally, the indicators related to working hours, safe and healthy living conditions, and access to immaterial resources obtained very negative social performance. The risk of an absence of environmental management systems was confirmed by the site-specific assessment that found an absence of a waste management system in the spinning (China) and the retailer (The Netherlands), but not in the shirt manufacturing in Bangladesh. Arguably, the unit performing worse in the risk assessment (the shirt manufacturing in Bangladesh) was performing better than the fabric manufacturer in Malaysia, and that of the alternative shirt manufacturer in Myanmar. Also, the risk of low salaries observed in the Bangladeshi garment sector was not confirmed in the sitespecific assessment, where the involved supplier complied with the minimum local wage.

In this study, the results were aggregated along the supply chain by using two different sets of working hours as activity variable. The aggregated results were helpful to identify the indicators that performed better or worse overall. However, the use of aggregated values can hide relevant social hotspots occurring only in one life cycle activity. For instance, the subcategory working hours obtained a positive result overall when considering the activity variable $\mathrm{T} 2$; however, it was identified as one of the main negative social hotspots in the supply chain. Additionally, the relevance of aggregating results is much lower when the goal of the study is to map the negative and positive social issues along the supply chain, aiming at improving the social conditions and contributing to the SDGs. For the same reason, this study did not weight the different indicators and sub-categories.

In summary, the S-LCA methodology still needs more developing efforts in order to be able to measure how much a product contributes to the fulfillment of the SDGs, but it is already useful to give an indication of which SDG is being positively or negatively affected by the product's life cycle, and what specific improvements could be done in the supply chain in order to accelerate the fulfillment of the SDGs. This is currently a tool for internal social management of businesses, and also for facilitating decision-making through the lens of the SDG framework.

\section{Conclusions}

This study proposed a classification framework to link the results of S-LCA with the SDGs. Such framework was applied to a case study on the textile sector, assessing the social life cycle impacts of a man's shirt whose supply chain takes place across five different countries. The classification provided a first step into the assessment of a product's contribution to the SDG. Nevertheless, methodological challenges were found, such as the different scope of the SDG indicators with respect to the S-LCA indicators. Future lines of research could focus on developing new SDG-related indicators, and a new set of PRP able to relate the scope of business activities to the current degree of global SDG accomplishment. Additionally, more detailed indicators measuring discrimination issues should be developed in the S-LCA framework.

The case study indicated that every supplier within the life cycle scored negatively in at least 4 indicators and their related SDGs, and one supplier (the spinner in China) scored negatively in almost half of the indicators and nine SDGs. Except for the spinner, every supplier scored positively (above compliance) in at least 3 indicators, mainly related to access to material resources, and social benefits provided to the workers. However, most of the suppliers presented negative performance rather than positive performance, indicating several opportunities for improvement, especially in goals 5,10 , and 11 . The main recommendations for the final Dutch retailer included the performance of more stringent audits to their suppliers, regarding weekly hours, overtime hours, freedom of association, gender equality, and waste management systems.

Acknowledgments The authors would like to thank the company that provided the data, as well as all the suppliers that participated in the study.

Open Access This article is licensed under a Creative Commons Attribution 4.0 International License, which permits use, sharing, adaptation, distribution and reproduction in any medium or format, as long as you give appropriate credit to the original author(s) and the source, provide a link to the Creative Commons licence, and indicate if changes were made. The images or other third party material in this article are included in the article's Creative Commons licence, unless indicated otherwise in a credit line to the material. If material is not included in the article's Creative Commons licence and your intended use is not permitted by statutory regulation or exceeds the permitted use, you will need to obtain permission directly from the copyright holder. To view a copy of this licence, visit http://creativecommons.org/licenses/by/4.0/.

\section{References}

Annapoorani SG (2017) Social sustainability in textile industry. In: Sustainability in the textile industry. Springer, pp 57-78

Anner M, Bair J, Blasi J (2013) Toward joint liability in global supply chains: addressing the root causes of labor violations in international subcontracting networks. Comp.Lab.L.\& Pol'y J 35:1

Asif A (2017) An overview of sustainability on apparel manufacturing industry in Bangladesh. Science Journal of Energy Engineering 5:112

Benoît Norris C, Traverso M, Valdivia S, Vickery-Niederman G, Franze J, Azuero L, Ciroth A, Mazijn B, Aulision D (2013) The methodological sheets for sub-categories in Social Life Cycle Assessment (SLCA). United Nations Environment Programme (UNEP) and Society for Environmental Toxicology and Chemiastry (SETAC)

Corona B, Bozhilova-Kisheva KP, Olsen SI, San Miguel G (2017) Social Life Cycle Assessment of a concentrated solar power plant in Spain: a methodological proposal. J Ind Ecol 21(6):1566-1577 
Eisfeldt F, Ciroth A (2017) Contribution of social life cycle assessment to reach the sustainable development goals. Medellín, VII International Conference on Life Cycle Assessment in Latin America 2017

Eisfeldt F, Ciroth A (2018) PSILCA-a product social impact life cycle assessment database. Database version 2. Database version 1:1-117

European Commission (2003) Communication from the commission to the Council and the European Parliament. Integrated Product Policy, Building on Environmental Life-Cycle Thinking. Brussels, 18.6.2003 COM(2003) 302 final

Goedkoop M, Martinez E, de Beer I (2017) LCA as the tool to measure progress towards the Sustainable Development Goals. Luxembourg, LIST

ILO (2017) Global estimates of child labour: results and trends, 20122016 (International Labour Office). International Labour Organization Geneva, Geneva

ILO (2018).Global Wage Report 2018/19: What Lies Behind Gender Pay Gaps

ISO (2006) 14040: environmental management-life cycle assessmentprinciples and framework. International Standards Organization. London: British Standards Institution

Jayawardana T, Perera M, Wijesena G (2014) Analysis and control of noise in a textile factory. Int J Sci Res Publ 4:1-7

Jordaan JA (2018) Foreign workers and productivity in an emerging economy: the case of Malaysia. Rev Dev Econ 22:148-173

JRC (2019) Sustainable Consumption. Indicators and assessment of the environmental impact of EU. EPLCA (Joint Research Center). In: . https://eplca.jrc.ec.europa.eu/sustainableConsumption.html. Accessed 9/12 2019

Kamal Y (2013) Corporate social and environment-related governance disclosure practices in the textile and garments industry: evidence from Bangladesh (Dissertation Thesis), RMIT University

Köksal D, Strähle J, Müller M, Freise M (2017) Social sustainable supply chain management in the textile and apparel industry - a literature review. Sustainability 9:100

Kühnen M, Hahn R (2017) Indicators in social life cycle assessment: a review of frameworks, theories, and empirical experience. J Ind Ecol 21:1547-1565

Lenzo P, Traverso M, Salomone R, Ioppolo G (2017) Social life cycle assessment in the textile sector: an Italian case study. Sustainability 9:2092

Martínez-Blanco J, Lehmann A, Chang Y, Finkbeiner M (2015) Social organizational LCA (SOLCA) - a new approach for implementing social LCA. Int J Life Cycle Assess 20:1586-1599

PWC (2015) Make it your business: engaging with the Sustainable Development Goals

Roos S, Zamani B, Sandin G, Peters GM, Svanström M (2016) A life cycle assessment (LCA)-based approach to guiding an industry sector towards sustainability: the case of the Swedish apparel sector. J Clean Prod 133:691-700
Scheyvens R, Banks G, Hughes E (2016) The private sector and the SDGs: the need to move beyond 'business as usual'. Sustainable Dev 24:371-382

United Nations (1992) Rio Declaration on Environment and Development A/CONF.151/26 (Vol. I) Chapter I, Annex I - UN Documents: Gathering a body of global agreements. Retrieved November 16 , 2018, from http://www.un-documents.net/rio-dec.htm

UNEP-SETAC Life Cycle Initiative (2009) Guidelines for social life cycle assessment of products. United Nations Environment Programme.ISBN:978-992

United Nations (2019a) About the Sustainable Development Goals. In https://www.un.org/sustainabledevelopment/sustainabledevelopment-goals/. Accessed 10/03 2019

United Nations (2019b) SDG indicators. Global indicator framework for the Sustainable Development Goals and targets of the 2030 Agenda for Sustainable Development. In: . https://unstats.un.org/sdgs/ indicators/indicators-list. Accessed 3/09 2019

Valente C, Rubach S, Askham C (2015) Establishing slow fashion-made in Norway. a business model for a more sustainable value chain for clothing. Sluttrapport fra et kvalifiseringsprosjekt med støtte fra RFF Oslofjordfondet. Retrieved from https://www.ostfoldforskning.no/ media/1009/750-1.pdf OR.10.15. Accessed 2/03 2019

van der Velden NM, Vogtländer JG (2017) Monetisation of external socio-economic costs of industrial production: a social-LCA-based case of clothing production. J Clean Prod 153:320-330

Vermeulen WJV (2018) Substantiating the rough consensus on concept of sustainable development as point of departure for indicator development. Handbook of Sustainability Indicators (S. Bell an, pp. 5990). Routledge/CRC Press.

Weidema B, Goedkoop M, Mieras E (2018) Making the SDGs relevant to business. PRé Sustainability \& 2.-0 LCA consultants

Wick I (2009) The social impact of the liberalised world market for textiles and clothing. B.Ruppert: Strategies of Trade Unions and Womens' Organisations.OBS-Workbook.Frankfurt am Main, Otto Brenner Foundation 62

Wulf C, Werker J, Zapp P, Schreiber A, Schlör H, Kuckshinrichs W (2018) Sustainable development goals as a guideline for indicator selection in Life Cycle Sustainability Assessment. Procedia CIRP 69:59-65

Zamani B, Sandin G, Svanström M, Peters GM (2018) Hotspot identification in the clothing industry using social life cycle assessmentopportunities and challenges of input-output modelling. Int J Life Cycle Assess 23:536-546

Publisher's note Springer Nature remains neutral with regard to jurisdictional claims in published maps and institutional affiliations. 